\title{
UM ESTUDO ACERCA DA FORMAÇÃO DO PROFESSOR UNIVERSITÁRIO.
}

\author{
NUNES, Neusa Clementina Rosa ${ }^{1}$ \\ SOUZA, Silvia Cristina $\mathrm{de}^{2}$
}

\section{Resumo}

O objetivo do presente trabalho é tratar da questão da formação do professor universitário no Brasil e apresentar o estudo de uma realidade específica que pretendeu conhecer as concepções dos professores universitários sobre sua prática docente, quais eram suas demandas de formação e como, no entender desses professores, a instituição a que estavam ligados poderia promover o atendimento dessas necessidades de formação. Esse artigo, ainda, busca apresentar alguns resultados e desdobramentos da pesquisa realizada.

\section{Introdução}

Ao iniciarmos uma análise sobre a formação do professor universitário, alguns aspectos devem ser considerados. Do ponto de vista legal, a formação inicial do professor universitário, ou aquela que antecede o ingresso do profissional na carreira acadêmica, deve ocorrer em nível de pós-graduação, preferencialmente em programas de mestrado e doutorado, sendo entendida, nesse contexto, como "preparação" para o exercício do magistério superior. Nesse sentido, ainda, o título de notório saber supre a exigência do título acadêmico.

Embora importante, a existência desse dispositivo que assegura uma "preparação" mínima para o exercício da docência superior não tem garantido, em termos práticos, a formação necessária para tal tarefa. $\mathrm{O}$ próprio conceito empregado para designar a forma como tal profissional será formado carrega uma certa superficialidade e descompromisso.

Os programas de pós-graduação, em especial os stricto sensu, embora possam explicitar nos seus objetivos a preparação para docência, notadamente articulam-se na formação de pesquisadores para áreas especificas. Tanto é assim que, no conjunto das atividades oferecidas e requisitos dos programas, os estudos sobre a prática e o próprio exercício da docência ocupam espaço muito limitado.

Como se observa (...) não há na legislação, de forma evidente, nenhuma referência à formação didático-pedagógica como pré-requisito para a formação, ingresso e promoção na carreira docente do magistério superior. Há que se considerar ainda que, não obstante, a referida lei estabeleça que a preparação para o exercício do magistério superior far-se-á em nível de pós-graduação, prioritariamente em programas de

\footnotetext{
${ }^{1}$ Centro Universitário Toledo de Araçatuba - UNITOLEDO

Rua Prestes Maia, 2505 - Araçatuba/São Paulo - CEP:16075-121

dirensino@toledo.br

${ }^{2}$ UNESP - Marília

Centro Universitário Toledo de Araçatuba - UNITOLEDO

Rua Afonso Pena, 1840 - Araçatuba/São Paulo - CEP:16060-040

silvia@toledo.br
} 
mestrado e doutorado, raros são os programas de pós-graduação que incluem formação para a docência na área da ciência a que se destinam. Esses cursos, que formam e titulam professores para o ensino superior, vêm contribuindo significativamente para a formação de pesquisadores, mas pouco ou quase nada para a formação do professor universitário. (NUNES, 2003, p.27)

De outra parte, as exigências postas tanto para os docentes, quanto para os alunos dos programas de pós-graduação, estão centradas na produção científica, situação semelhante ao que ocorre dentro dos cursos de graduação, visto que os critérios de avaliação desses, na mesma medida, supervalorizam tal produção, de forma que

ensino e pesquisa passam a ser atividades concorrentes, e como os critérios de avaliação premiam apenas a segunda, uma cultura de desprestígio à docência acaba sendo alimentada no meio acadêmico, comprometendo a almejada indissociabilidade ensino-pesquisa-extensão (PACHANE E PEREIRA, 2004, [s.p.]).

Em termos gerais, é possível perceber que as políticas de formação de docentes para o ensino superior pouco contribuíram no sentido de garantir efetivamente uma formação preocupada e comprometida com os aspectos didático-pedagógicos. Diante do quadro apresentado e da urgência em resolver questões resultantes da formação inicial do docente universitário, algumas Instituições de Ensino Superior - IES - tem encontrado na formação continuada de seus quadros um modo de suprir as deficiências apresentadas.

Inserido nesse cenário, o Centro Universitário $X^{3}$, instituição de ensino superior privada, situada no interior do Estado de São Paulo, iniciou, no final da década de 1990, um programa de formação pedagógica com vistas a atender as demandas de seus docentes, em especial aqueles que não tiveram, dadas suas condições de formação inicial, contato com questões relativas aos processos de ensino e de aprendizagem, bem como outras tantas subjacentes a tarefa educativa. Contudo, a proposta implementada, naquele momento, foi resultado de uma iniciativa dos órgãos dirigentes da instituição, não sendo, portanto, fruto de uma demanda declarada ou explicitada pelos docentes, mas percebida principalmente pelos resultados da avaliação institucional.

Em decorrência dessas discussões, a administração percebe a necessidade de sistematização de um programa de formação continuada e, a fim de estruturar um trabalho com bases teórico-investigativas, iniciou um programa em que mestres e doutores em Educação trouxessem algum tipo de auxílio no tocante ao ensino, à aprendizagem, à avaliação e à relação professor/aluno (questões consideradas mais críticas na avaliação institucional aplicada aos alunos). A participação nas atividades realizadas, no entanto, contava, na maioria das vezes, com a presença dos professores licenciados e não dos bacharéis que, na ótica dos alunos, deveriam melhorar a sua prática em sala de aula. (NUNES, 2003, p.40)

No presente artigo buscaremos apresentar o estudo empreendido por NUNES (2003) que teve como objetivo principal buscar entender o que pensavam os professores do Centro Universitário $\mathrm{X}$ sobre sua prática, seus conflitos e quais eram suas demandas de formação. $\mathrm{O}$ estudo em questão propiciou um entendimento acerca de como eram recebidas as ações e iniciativas de formação implementadas pela IES e os resultados e impactos sobre

\footnotetext{
${ }^{3}$ Nome fictício.
} 
o fazer pedagógico dos docentes. $\mathrm{O}$ artigo pretende, ainda, apresentar brevemente a situação atual e as repercussões advindas do estudo de NUNES.

\section{Desenvolvimento}

Ao analisar as políticas recentes de formação continuada de professores, NUNES (2003) alerta que, embora tenha sido evidenciada a ineficiência das políticas e estratégias postas em prática na década de 1980, principalmente em função do modelo baseado em ações isoladas, fragmentadas e desarticuladas, tal constatação não serviu para reformular a concepção de formação que prevaleceu nos anos de 1990, sustentada em atividades múltiplas, descontínuas e desvinculadas da prática dos educadores.

Atualmente, muitas iniciativas com relação ao problema da pedagogia universitária têm sido tomadas pelas universidades com o objetivo de discutir com os docentes a questão do conhecimento pedagógico e de sua utilização no desempenho profissional, enquanto professor do ensino superior. Essas ações, no entanto, quase sempre são identificadas como de efeito diminuto sobre a prática docente. Uma das críticas mais comumente feitas aos programas de formação contínua refere-se ao processo de elaboração dessas propostas, que, na maioria das vezes, são pensadas "de cima para baixo", com a completa exclusão dos docentes. A expectativa de que, através dessas ações, ocorreria uma rápida adequação das práticas docentes às mudanças pretendidas, não tem se confirmado, provavelmente porque esses programas/projetos são geralmente organizados por especialistas, situados fora do contexto escolar ao qual os programas se destinam e, principalmente, sem considerar as necessidades dos professores.

No dizer de TARDIF (2000, p.230):

(...) um professor de profissão não é somente alguém que aplica conhecimentos produzidos por outros, não é somente um agente determinado por mecanismos sociais: é um ator no sentido forte do termo, isto é, um sujeito que assume sua prática a partir dos significados que ele mesmo lhe dá, um sujeito que possui conhecimentos e um saber fazer provenientes de sua própria atividade e a partir dos quais ele a estrutura e a orienta.

Dessa forma, qualquer proposta de formação (inicial ou contínua), deve registrar o ponto de vista do professor, sua subjetividade, seu conhecimento e saber-fazer, mobilizados em suas ações cotidianas. Problematizar a prática docente como ponto de partida para identificar necessidades formativas é promover, entre os professores, oportunidades de diálogo sobre suas visões de ensino e suas práticas, de modo a situar e teorizar sua história, suas experiências, sua afetividade, sua emoção, suas crenças e valores como fatores que o constituem como professor.

A realidade da instituição estudada por NUNES não difere das demais IES brasileiras. Um ponto que merece ser analisado diz respeito aos cursos oferecidos. Grande parte deles destina-se a formação de bacharéis, nesse sentido, muitos de seus docentes também são bacharéis, na sua maioria especialistas, mestres ou doutores sem formação pedagógica. Alguns deles profissionais liberais, desempenhando as funções de professores universitários, ministrando disciplinas relacionadas com a formação específica de seu 
desempenho profissional. É justamente sobre essa realidade que os programas de formação continuada de professores universitários tentam incidir, ou seja, buscam, a partir de um entendimento de que os bacharéis não têm a devida formação pedagógica, suprir as deficiências detectadas, melhorando o que se convencionou chamar de "didática do professor".

Diante desse quadro e dessas considerações, colocam-se os seguintes questionamentos: Como se relaciona o professor bacharel com sua tarefa de educador? Como se fez professor do ensino superior? Que conflitos enfrentou/enfrenta na sua prática docente? O que fez/faz ante as dificuldades enfrentadas? Que tipo de apoio poderia a instituição oferecer para o aprimoramento de sua prática docente?

NUNES (2003), interessada em responder aos questionamentos apresentados, analisou a situação dos docentes do Centro Universitário X. Para tanto, empreendeu uma pesquisa na qual buscou conhecer e compreender quais as concepções e demandas expressas pelos professores no que se referia a sua atuação docente.

Foram pesquisados 149 (cento e quarenta e nove) professores dos 12 (doze) cursos oferecidos, naquele momento, pela IES (Direito, Administração, Comércio Exterior, Ciências Econômicas, Ciências Contábeis, Hotelaria, Turismo, Sistemas de Informação, Jornalismo, Educação Física, Letras e Pedagogia). A pesquisa contou com aplicação de questionário e reunião em grupo e partiu de uma pergunta chave: Quais as dificuldades encontradas por você, professor, no seu "que fazer" docente?

Do total dos questionários remetidos, 67 (sessenta e sete) ${ }^{4}$ foram devolvidos. Dos docentes que responderam a pergunta inicial, $87 \%$ apontaram a questão da falta de preparo do aluno para a educação superior como o principal problema enfrentado no cotidiano da sala de aula, seguido de falta de tempo para o professor, dificuldades pedagógicas e burocracia.

A partir das respostas apresentadas buscou-se o aprofundamento da pesquisa, tomando-se a questão da falta de preparo do aluno como foco de análise. Os professores foram convidados a participar de uma reunião, cuja adesão foi espontânea. A intenção da reunião era buscar detectar elementos que pudessem qualificar o que, na fala dos professores, se traduzia em "falta de preparo dos alunos".

Na reunião foi apresentado o resultado da primeira investigação e os presentes puderam verbalizar suas concepções, norteados por três questões: como descreviam a falta de preparo dos alunos, a que atribuíam essa falta de preparo e como e o que propunham para superar o problema.

Os argumentos levantados pelos professores podem ser assim sintetizados:

\footnotetext{
${ }^{4} 17$ professores licenciados e 50 bacharéis. Do universo de bacharéis, 5 possuíam formação pedagógica em curso de Especialização em Didática do Ensino Superior.
} 
- perguntados sobre como se materializa a falta de preparo dos alunos, os professores descrevem como: falta de concentração para leitura; falta de habilidades para pesquisa e registro de dados; falta de conceitos prévios; escritas com frases retiradas de partes de textos sem nenhum sentido; não acompanhamento das aulas; dificuldades de leitura e interpretação; incapacidade de realizar tarefas.

- em relação à questão a que atribuem a falta de preparo dos alunos, destacam: à educação básica, que não desenvolve as habilidades necessárias para a continuidade dos estudos; aos próprios alunos porque são imaturos e desinteressados; aos responsáveis pela orientação na elaboração dos planos de ensino; à faculdade, que oferece um ensino reprodutivista e, também, não fornece aos alunos informações sobre os cursos e as possibilidades de trabalho depois da formação acadêmica.

- como e o que propõem para superar a falta de preparo dos alunos: reuniões de professores para estudo e troca de experiência com os colegas; reuniões sistematizadas e fundamentadas, com objetivo específico de melhorar o trabalho docente; trabalho de nivelamento com os alunos ingressantes, realizados pela faculdade; planejamento das atividades docentes, prevendo reuniões para orientação na elaboração de planos de ensino e atividades de estágio; realização de atividades que ofereçam aos discentes informações esclarecedoras sobre o curso escolhido e as oportunidades de trabalho dele decorrentes.

Havia uma suposição inicial de que os professores não se interessavam em participar de programas de formação continuada, o que foi descartado ao final da pesquisa. As dificuldades enfrentadas em sala de aula, conforme depoimentos dos professores, os incomodavam e estes declararam que, havendo oportunidade, gostariam de buscar formas de superá-las. Por outro lado, o que se pode constatar é que a instituição oferecia aos professores, a título de formação continuada, os tradicionais cursos sazonais de atualização, capacitação, treinamento e reciclagem do professor em serviço, analisados pelos professores, na pesquisa, como sendo inadequados para a ampliação da qualidade do trabalho acadêmico.

As convocações esporádicas para reuniões gerais ou para cursos, em que os professores participavam como meros expectadores, sem nada dizer, mas com o dever de mudar a sua prática a partir daí, demonstraram a influência da racionalidade técnica, decorrente de uma cultura profissional marcada pela valorização do conhecimento livresco e por atividades que excluíam a reflexão critica e coletiva sobre a própria prática pelo professor, como forma de desenvolvimento profissional.

Foi possível concluir, em função dos dados analisados, que a forma de funcionamento dos cursos e a organização institucional também auxiliavam a produção de uma formação fragmentada do acadêmico e do professor. Um exemplo disso pode ser observado nas entrevistas realizadas com os professores, em que estes manifestaram a compreensão de que o ensino era a principal função da universidade, não demonstrando perceber que a formação acadêmica não depende somente do ensino (da retenção de conhecimentos já produzidos), mas também da pesquisa (produção de novos conhecimentos) e da extensão (troca de conhecimentos entre a universidade e a sociedade). 
A superação da visão fragmentada do professor sobre questões que envolvem o processo ensino-aprendizagem passaria, portanto, pela própria rearticulação da instituição.

Esse mesmo estudo revelou ainda a falta de preparo do aluno para o ensino superior, decorrente principalmente das lacunas da escolaridade no ensino básico, sério problema a ser enfrentado. Não basta, no entanto, constatá-lo. Cabe à universidade, enquanto instituição social e no exercício desta função, pautar-se pela idéia de um conhecimento guiado pelas suas próprias necessidades e uma forma de enfrentar esse desafio é a construção coletiva do projeto institucional, recuperando as raizes da instituição social que é a universidade e questionando criticamente as funções que hoje se espera que ela exerça, enquanto entidade administrativa (ANASTASIOU E PIMENTA, 2002, p. 174).

Nesse sentido, observou-se alguns ensaios havidos na instituição investigada, por meio de seus projetos de pesquisa e extensão. Porém, pareceu necessário inseri-los como parte integrante do projeto institucional, de modo a influenciar o ensino, ou seja, que fossem projetados e desenvolvidos como parte integrante do projeto político-pedagógico da instituição para cumprir, de fato, o papel que lhes cabe na educação dos alunos.

Identificou-se ainda nos depoimentos indicativos que os professores estavam dispostos a mudar a sua prática docente, buscando superar, sobretudo, as dificuldades advindas do próprio fenômeno educacional. Nesse sentido, cabe lembrar que os aspectos profissionais discutidos e refletidos coletivamente oportunizam a sensibilização de que o processo ensino-aprendizagem não tem sentido se não for um caminho de parceria, envolvimento e que, como observa ASSIS (2001), o trabalho coletivo reforça as possibilidades de êxito das iniciativas individuais.

Vale lembrar, no entanto, que alguns fatores interferem de maneira significativa na operacionalização do trabalho docente. Podemos destacar, por exemplo, a necessidade apontada pelos professores de encontros para discutir as práticas docentes, para troca de experiências e para reflexões coletivas que busquem aprofundar questões teóricometodológicas, indispensáveis como subsídios à reflexão sobre a prática pedagógica.

Quanto à instituição investigada, pode-se dizer que esta apresentava, e apresenta, uma infra-estrutura física e tecnológica condizente com as necessidades dos alunos e professores. Sua estrutura organizacional, conforme registrado nos documentos, atendia, e atende, a todos os quesitos legais exigidos para uma instituição dessa natureza.

No entanto, embora fossem observados avanços em sua caminhada, carecia de um projeto institucional, não enquanto peça burocrática (esse existia!), mas sim de um projeto construído com a participação de todos os segmentos que compunham a instituição, e que orientasse os processos de tomada de decisão e de avaliação de políticas, programas, projetos e ações, em todos os âmbitos, conforme propõe FUSARI (1999, p. 222-223): 
comprometida com um projeto de educação escolar a favor da eqüidade, da justiça, do direito e da convivência com o diferente;

- Apesar de levarem em consideração as diretrizes nacionais, estaduais e municipais de educação, sejam menos massificadas e mais personalizadas, dando voz à equipe e às necessidades da comunidade;

- Sejam mais próximas de um paradigma que propicie a formação do educador como um processo permanente, composto pela articulação entre a formação inicial e a contínua;

- Reforcem a idéia de que o processo de formação e desenvolvimento profissional está mais centrado no próprio sujeito/grupo de educador(es) do que nas "modalidades" de formação contínua;

- Sirvam de base de sustentação do Projeto Político Pedagógico da escola como eixo norteador da educação dos educandos e, também, dos educadores da escola;

- Se organizem a partir de paradigmas que defendam uma concepção de conhecimento que tenha na sua base a articulação entre prática, teoria e prática ou ação pensamento-sentimento e ação;

- Assumam os limites e possibilidades das ações de formação contínua, colocando nelas uma possibilidade relativa de transformação da prática profissional dos educadores;

- Considerem a gestão escolar democrática como uma variável que pode ser uma grande aliada do processo de formação do educador em serviço.

Essas propostas permitem pensar possibilidades para uma universidade voltada para a qualidade, desejo da instituição em foco, bem como buscar o novo na reflexão crítica, por meio do ensino e da investigação científica.

A prática pedagógica desenvolvida com base nessas preocupações, se assumida pela escola, permitirá aos professores envidar esforços em propostas de intervenção pedagógica nas várias esferas do educativo para enfrentamento dos desafios colocados pelas novas realidades do mundo contemporâneo (LIBÂNEO, 1996). O mesmo esforço é válido também para os coordenadores de curso, gestores que são influenciados pela racionalidade técnica e, para os quais, a falta de contato com conhecimentos pedagógicos impede a realização de um trabalho de gestão que possa oferecer apoio aos professores.

\section{A repercussão da pesquisa ou o momento atual}

NUNES afirmou no seu trabalho que no que diz respeito à capacitação docente, a instituição desenvolve um plano, com acompanhamento da direção, porém elaborado também sem a participação dos professores (2003, p.55).

A IES, até aquele momento, havia implementado uma série de ações de formação docente, que iam desde o incentivo a participação em programas de pós-graduação lato e stricto sensu até a organização de cursos e palestras que buscavam qualificar o fazer pedagógico. Contudo, como já foi mencionado, tais iniciativas partiam dos órgãos dirigentes, não havendo, portanto, a participação do professor nesse processo de proposta de formação.

O grande resultado do estudo de NUNES foi justamente conhecer as reais demandas dos docentes e compreender que um programa de formação continuada requer da 
instituição muito mais que um conjunto de cursos e palestras esporádicas, proposto (e por vezes imposto) diante de um pretenso entendimento acerca das necessidades existentes.

Embora o universo de professores pesquisados não constitua a totalidade daqueles que atuavam na instituição, os dados coletados serviram para indicar, com relativa precisão e confiabilidade, o que pensavam e como entendiam sua tarefa docente. Serviram, ainda, para, se não determinar, ao menos apontar suas demandas de formação e o que esperavam, nesse sentido, em termos de ações institucionais.

Com base nesses indicativos, a IES vem trabalhando no sentido de criar uma política institucional de formação continuada, iniciativa que vem se desenhando nos últimos anos. Contudo, entende que se trata de um processo lento, complexo e que não se concretiza sob forma de regulamento ou conjunto de regras dispostas nos documentos oficiais da instituição, mas principalmente pela participação efetiva dos professores, num modelo aberto e democrático.

Nesse sentido, tem promovido e incentivado o contato de docentes, coordenadores e dirigentes, inclusive definindo um calendário de encontros e formação.

Foi criado, ainda, um grupo de estudos, por iniciativa dos próprios docentes, como consequiência imediata da participação na pesquisa de NUNES (2003). O grupo em questão encontra-se em fase de reestruturação, onde estão sendo definidos os eixos e linhas de pesquisa e estruturados diferentes grupos ${ }^{5}$.

Existe, atualmente, um grande número de docentes da Instituição matriculados no curso de pós-graduação em Docência do Ensino Superior, contando, inclusive, com incentivo financeiro da IES. Curiosamente muitos desses docentes são remanescentes do grupo que participou da pesquisa de NUNES, sendo muitos deles bacharéis.

Descrevemos brevemente alguns exemplos dos resultados e do alcance do trabalho de NUNES. Contudo, sua contribuição pode não ser totalmente percebida sob forma de ações concretas e objetivas ou, ainda, quantificáveis. Entretanto, embora não fosse o objetivo principal, foi capaz de imprimir uma nova maneira de pensar a questão docente na IES, tanto no que se refere aos seus dirigentes, como os próprios professores.

\section{Conclusão}

Parece-nos que as IES, de modo geral, têm muito claro para si o que é preciso para que o professor possa dar uma boa aula ou ser um bom profissional. Desses professores tem-se exigido uma postura comprometida com a aprendizagem efetiva dos alunos, baseada numa concepção ou abordagem pedagógica que privilegie a construção do conhecimento a partir da significação e do contato com o objeto do estudo, de forma que os alunos expressem suas idéias, manifestem seus desejos e, principalmente, sejam ouvidos.

\footnotetext{
${ }^{5}$ Os grupos em fase de estruturação destinam-se a estudos e pesquisas.
} 
É certo que as IES devam almejar apenas, e tão somente, uma educação de qualidade. Este também é um direito do aluno e deve ser uma preocupação permanente dos professores.

Todavia, cabe questionar: Quem forma esse professor? Qual formação tem sido oferecida? Qual abordagem tem sido adotada? Quais os desejos e necessidades desses professores? Quem os ouve?

A formação que antecede o ingresso do docente no ensino superior pouco ou quase nada contribui no sentido de aproximá-lo daquilo que as IES esperam e desejam, principalmente no caso dos bacharéis. Na mesma medida, os modelos de formação continuada oferecidos por essas mesmas Instituições ignoraram justamente aquilo que lhes parece mais caro (quando pensam na aprendizagem dos alunos): o diálogo, a participação, a significação e acabam por impor um modelo prescritivo e altamente centrado na idéia de que cabe ao professor, e apenas a ele, resolver os problemas de ordem pedagógica a partir do aporte institucional (materializado em cursos, palestras e congêneres).

Esse descompasso entre o dito e o feito tem permeado a atuação de grande número de instituições de ensino superior brasileiras, atuação marcada pela omissão em relação a formação de seus professores.

No estudo apresentado, pudemos perceber movimentos no sentido de superar uma situação bastante semelhante. Embora circunscrito a uma realidade específica, o estudo apontou alguns caminhos que podem, de alguma forma, contribuir para uma mudança importante e necessária, quais sejam: elaboração de projetos coletivos de trabalho, com a participação de todos os envolvidos e a criação de condições estruturais para o desenvolvimento desse trabalho.

Embora o presente trabalho seja apenas um pequeno recorte de uma pesquisa mais ampla, pretende ser, também, um convite para o aprofundamento do importante debate sobre a questão da formação do docente do ensino superior.

\section{Referências Bibliográficas}

Anastasiou, L.G.C. y Pimenta, S.G. (2002). Docência no ensino superior. São Paulo: Editora Cortez.

Assis, M.A.L.G.F. (2001). Formação pedagógica numa instituição de ensino superior: impasses e desafios. Dissertação de Mestrado. Piracicaba: Universidade Metodista de Piracicaba. Faculdade de Educação.

Cunha, M.I. (1998). O professor universitário na transição de paradigmas. Araraquara: JM Editora.

Fusari, J.C. (1999). Avaliação de modalidades convencionais e alternativas de educação contínua de educadores: preocupações a serem construídas. En: Bicudo, M.A.V. y Silva 
Junior, C.A. (Orgs.), Formação do educador e avaliação educacional: formação inicial e contínua. São Paulo: UNESP.

Libâneo, J.C. (1996). Que destino os educadores darão a pedagogia? En: Pimenta, S.G. (Coord.), Pedagoria, ciência da educação? São Paulo: Cortez, 1996.

Nunes, N.C.R. (2003). A formação continuada do professor do ensino superior : um compromisso institucional. Dissertação de Mestrado. Piracicaba: Universidade Metodista de Piracicaba. Faculdade de Educação.

Pachane, G.G. e Pereira, E.M.A. (2004). A importância da formação didático-pedagógica e a construção de um novo perfil para docentes universitários. Revista Iberoamericana de Educação, (33)4.

Tardif, M. (2002). Saberes docentes e formação profissional. Petrópolis: Vozes. 